\title{
THE USE OF A CONTROLLED MULTIPLE QUASI-STATIC INDENTATION TEST TO CHARACTERISE THROUGH- THICKNESS PENETRATION OF COMPOSITE PANELS
}

\author{
J. Sirichantra, S. L. Ogin*, D.A. Jesson \\ Faculty of Engineering and Physical Sciences, Department of Mechanical, Medical and \\ Aerospace Engineering, University of Surrey, Guildford, GU2 7XH, UK \\ *Corresponding author. Tel.: +44 1483 689614, Fax: +44 1483686291 E-mail address:

\section{S.Ogin@surrey.ac.uk}

\begin{abstract}
During the quasi-static indentation of thin composite panels, well-defined flaps (sometimes called "petals") can develop on the exit face as a consequence of through-thickness penetration of the panel; such flaps can also be seen in impact tests. The flaps develop as four triangles, with the apex of each triangle at the point of impact. In this work, thin panels of CFRP with a 0/90 configuration have been subjected to quasi-static indentation tests and the development of the flaps has been monitored. The results show that the dependence of the flap compliance is proportional to the square of the flap length, which is in agreement with theoretical predictions. The determination of the compliance/crack-length relationship enables a toughness value for fracture of the composite panel to be derived that is directly relevant to through-thickness penetration of the panel.
\end{abstract}

Key words: A. Carbon fibre; A. Fabrics/textiles; Quasi-static indentation test

\section{Introduction}

The formation of "flaps" (also sometimes called "petals" [e.g. 1]) is a feature common to the throughthickness penetration of thin woven fabric reinforced CFRP panels when tested in drop-weight (lowvelocity) impact tests [2], in ballistic impact tests [3], or in the quasi-static indentation tests used here. This work forms part of a study on the effect of carbon nanotubes on flap formation and throughthickness penetration of woven fabric reinforced CFRP panels. In this part of the study, a quasi-static indentation test (where an impactor is driven at a controlled velocity into a specimen) has been used to 
investigate the behaviour of the flaps and a method has been developed to derive a toughness value for fracture of the composite across the fabric tows. This use of the quasi-static indentation test in relation to flap development is rather similar to the use of similar tests to measure the fracture toughness of ceramics [e.g. 4-5].

Figure 1 shows the development of such flaps in a plain woven fabric CFRP laminate specimen for impactor displacements of $8 \mathrm{~mm}$ and $12 \mathrm{~mm}$, where the flap (crack) length, $a$, has developed from approximately $8 \mathrm{~mm}$ to $10 \mathrm{~mm}$. In addition to the formation of the flaps (which require extensive tow fracture), additional types of damage occur which are similar to the types of damage found in lowvelocity and ballistic velocity impact tests, including delamination, matrix cracking and splitting [see e.g. 6-8]. However, as first approximations, we suppose (i) that the major energy absorbing mechanisms during the development of the flaps and the through-thickness penetration (i.e. perforation) of the specimen are the tow fractures along the edges of the flaps, and (ii) that the flaps behave in a linear-elastic manner and that any additional damage due to quasi-static indentation (in the form of matrix cracking, delamination etc) has only a small effect on the compliance/crack length relationship - this is justified subsequently in Section 3. With the aid of these approximations, an expression for the compliance of the flaps is derived and this expression is used for comparison with experimental measurements. The compliance/crack length relationship from the quasi-static indentation tests enables a toughness measurement relevant to the through-thickness penetration of the specimen to be derived which can be compared with independent measurements of the toughness of the woven fabric reinforced CFRP composite. The methodology is developed first with experiments on PMMA (Perspex).

\section{Measurement of the toughness of PMMA using a quasi-static indentation test}

\subsection{Introduction}

The purpose of the work described in this section was to carry out experiments using thin PMMA specimens in order to compare experimental predictions of the flap compliance as a function of flap (crack) length with theoretical predictions. In addition, the quasi-static indentation test was used to measure the toughness of the PMMA, for comparison with single edge notch measurements. 


\subsection{Compliance of a 'flap'}

Figure 1 shows that for a thin composite specimen based on a plain woven fabric CFRP, with all the tows arranged in orthogonal directions (i.e. overall a 0/90 laminate), each flap can be considered to be one-quarter of a square; this shape is maintained as the impactor is driven into the panel and the flaps grow in area as the damage extends. Figure 2 shows a sketch of such a flap, which we assume here is loaded throughout the test at its apex by a load $P^{\prime}$ (note that $P^{\prime}=P / 4$, where $P$ is the total load applied by the impactor to all four of the flaps); in reality the exact position of the point of loading of the flaps is likely to vary slightly as the impactor penetrates the specimen and the contact point moves on the hemispherical surface of the impactor. The flap has two edges (where the tows have fractured) having a length $a$, with an included right-angle. The flap has a length $L_{l}$ in the z-direction, so that the base of the flap triangle has a length a/ $\sqrt{ } 2$.

The flap is modeled as a cantilever beam acted on by the load $P^{\prime}$. However, for quasi-static indentation or impact tests of any type, the impactor is generally driven into a circular specimen and the flaps develop with the apex of the triangles at the centre of the circle i.e. where the impactor is driven into the specimen. Consequently, the flaps that develop are not rigidly constrained at the base of the flaps. To account for this lack of constraint, the flap is considered to have a rectangular extension having a length $\alpha L_{l}$ attached to the base (as shown in Figure 2), where $\alpha$ is an empirical correction factor derived from experimental compliance measurements. The flap-plus-extension has a thickness $t$, and is fabricated from material with a flexural modulus, $E$. The deflection of the flap-plus-extension as a consequence of a load $P^{\prime}$ acting perpendicular to the flap, at the flap apex, can be derived using the method of superposition for nonprismatic beams [e.g. 9]. The total deflection, $\delta_{A}$ at the end of the flap is equal to the sum of the deflections of the triangular and rectangular sections and is given by

$$
\delta_{A}=\frac{1}{2}\left(2 \alpha^{3}+3 \alpha^{2}+9 \alpha+3\right) \frac{P^{\prime} a^{2}}{E t^{3}}
$$

Consequently, the compliance of the flap-plus-extension, $C_{\text {flap }}$, in relation to the load, $P^{\prime}$, is given by 


$$
C_{\text {flap }}=\frac{1}{2}\left(2 \alpha^{3}+3 \alpha^{2}+9 \alpha+3\right) \frac{a^{2}}{E t^{3}}
$$

The validity of Equation 2 has been demonstrated using specimens cut from PMMA sheets (obtained from ICI plc) having an average thickness of $2.26 \pm 0.03 \mathrm{~mm}$ and with the shape shown in Figure 2. The crack (i.e. flap) lengths, $a$, and the rectangular extension lengths, $\alpha L_{l}$, that were investigated are shown in Table 1 with a value of $\alpha=1$. The specimens were gripped rigidly along the length $\mathrm{AB}$ and a load (P') was applied at the apex of the flap. The load-displacement response was recorded so that the specimen compliance could be derived. In addition, the flexural modulus of the PMMA was measured in independent four-point bend tests and was found to be $3.3 \pm 0.3 \mathrm{GPa}$. Figure 3 shows very good agreement between the experimentally measured compliance values for the flap-plus-extension compared to the predicted values (using Equation 2). This approach is only valid for situations where the flap length is significantly greater than the flap thickness, so that simple beam theory applies.

\subsection{Derivation of a toughness value from a quasi-static indentation test}

In a quasi-static indentation test on a specimen containing flaps, the total displacement of the impactor recorded by the testing machine consists of the central deflection of the disk, which is held rigidly at its circumference, together with the displacement of the flaps-plus-extensions. If the area of the flaps-plusextensions is small compared to the overall impacted disk area, which will generally be the case for quasistatic indentation tests or impact tests, then the total deflection, $\delta_{\text {total }}$, measured by the testing machine is

$\delta_{\text {total }}=\delta_{\text {disk }}+\delta_{\text {flap }}$ where $\delta_{\text {disk }}$ is the deflection of the disk without flaps under a central point load and $\delta_{\text {flap }}$ is the deflection of the flaps (including extensions). Figure 4 shows a sketch of a cross-section of a specimen for the same quasi-static indentation force, $P$, (a) without flaps, and (b) the same specimen if flaps have developed. The deflection due to the flaps-plus-extensions for any flap length can be derived by subtracting the deflection due to the undamaged disk from the total deflection due to the disk and flaps, making the assumption that any damage to the disk outside of the flap area has a negligible effect on these deflections. 
If the compliance-flap length relationship can be established in this way, it is then possible to derive a toughness value when sufficient load is applied to cause the flaps to grow using the equation:

$$
G_{c}=\frac{P_{\max }^{2}}{2 t} \frac{d C}{d a}
$$

where $P_{\max }$ is the load required to grow flaps of length $a$.

This approach for measuring toughness in quasi-static indentation tests has been tested on specimens of PMMA. Circular specimens, with an overall diameter of $140 \mathrm{~mm}$, were locked into a rig which has the dimensions suggested by the CRAG manual [10] for impact tests; details of the rig have been presented elsewhere [11]. In this study, the rig has been used with a quasi-static indentation velocity of $0.08 \mathrm{mms}^{-1}$, using a glass impactor having a diameter of $15.7 \mathrm{~mm}$. The load-deflection response for flaps of different lengths was measured by cutting notches in the shape of a cross into the circular specimens from an initial small circular hole (diameter $4 \mathrm{~mm}$ ) drilled into the centre of the specimens (see Figure 5). Notch (i.e. flap) lengths from $8 \mathrm{~mm}$ to $12 \mathrm{~mm}$ were cut, enabling the compliance of the flaps-plus-extensions to be measured for this range of flap lengths (after subtracting the behaviour of the disk with the initial small circular hole). Toughness measurements for crack growth in the PMMA were made for 5 crack (flap) lengths, in the range $8 \mathrm{~mm}$ to $12 \mathrm{~mm}$, with two specimens tested at each crack length. For the toughness measurements, the 4 notches forming the four flaps were sharpened at the notch root using a fresh scalpel blade.

Typical load-displacement curves for the disks with flaps of different lengths $(a)$ are shown in Figure 6(a). It can be seen that these thin disks behave in a non-linear elastic manner, in accordance with the behaviour of circular thin plates under a centre point load [12-13]. Figure 6(b) shows graphs of the load on one flap, $P^{\prime}$, plotted versus the flap deflection, $\delta_{\text {flap }}$, where the flap deflection has been derived using the expression $\delta_{\text {flap }}=\delta_{\text {total }}-\delta_{\text {disk }}$ (in this case, $\delta_{\text {disk }}$ is the load-displacement curve of a similar disk containing the initial circular hole). As Figure 6(b) shows, the flap load/deflection behaviour for a given flap length is linear, as expected (Equation (1)). For a given applied load, the deflection should be proportional to the flap length squared, a relationship which is obeyed reasonably well given that for these experiments with PMMA, the specimen must be removed repeatedly to enlarge the notch lengths manually, and then 
replaced in the same position. The compliance measurements derived from such results are plotted against flap (i.e. crack) length in Figure 7 for two specimens where the solid line is an expression of the form $C_{\text {flap }}$ $=0.38 a^{2} \mathrm{~m} / \mathrm{N}$. Consequently, use of Equation (2) suggests the value of $\alpha$ (the empirical correction factor; Section 2.2) for these PMMA specimens when subjected to the quasi-static indentation test is $\alpha \approx$ 1.5 .

For the toughness measurements, the loads for unstable crack propagation, and the resulting toughness measurements derived using Equation (3), are shown in Table 2, where the results for two specimens are shown for each crack length and Figure 8 shows these results graphically. The average toughness derived from all of these measurements is $0.43 \pm 0.06 \mathrm{~kJ} / \mathrm{m}^{2}$, where the uncertainty is the standard deviation. For comparison, single edge notch measurements of the toughness of the same PMMA material were made following ASTM standard E 399-90; the average mode I toughness was found to be $0.32 \pm 0.07 \mathrm{~kJ} / \mathrm{m}^{2}$, where again the uncertainty is the standard deviation. The toughness determined by the quasi-static indentation test has been found to be about $34 \%$ higher than for the SEN test; this difference is believed to be a consequence of mixed-mode fracture in the indentation test. During the quasi-static indentation tests on PMMA, it was rare to find a specimen within which the four sharpened notches had not propagated unstably to complete fracture. However, a rare example of a crack which did not propagate to complete failure is shown in Figure 9, where the transparency of the PMMA enables the crack profile between the impact and exit faces of the specimen to be seen. The curved profile of the crack shows that the crack is longer on the exit face of the specimen than on the impact face. For single edge notch experiments where the crack is growing in pure mode I, the length of the crack on both surfaces of the specimen is the same, and the crack front is expected to be planar. It is clear that the quasi-static indentation test does not produce pure mode I crack growth, and it is therefore not surprising that the toughness measurements differ. It is interesting to note that Archer and Lesser [14] found the mode II fracture toughness of PMMA to be about 6.7 times larger than the mode I fracture toughness, suggesting that the mode II toughness is 45 times larger than the mode I toughness. Consequently, a mode mixity with even a small proportion of mode II is likely to increase the measured toughness significantly. 


\section{Application of the quasi-static indentation toughness measurement to a thin woven fabric CFRP panel}

In this section, the methodology used in Section 2 for measuring the toughness of a thin plate using a quasi-static indentation test is applied to a CFRP laminate. Specimens were fabricated from six layers of plain woven carbon fibre fabric, using a wet lay-up technique. The fabric used was AW186/000/1000, 0.3 $\mathrm{mm}$ thick and $203 \mathrm{~g} / \mathrm{m}^{2}$ in weight (from Fothergill Engineered Fabrics Ltd) with all the plies in a 0/90 configuration; the epoxy resin matrix was a Bisphenol-A 67 resin 300 (Shell Epikote 828), with nadic methyl anhydride (NMA) hardener and Ancamine K61B catalyst, in the ratio 100:60:4 by weight, respectively. Details of laminate fabrication have been given elsewhere [15]. The laminate panels, with dimensions $450 \mathrm{~mm} \times 450 \mathrm{~mm}$, were cured at a temperature of $100{ }^{\circ} \mathrm{C}$ for 3 hours under a pressure of approximately $7 \mathrm{kPa}$. The volume fraction of fibre in the laminates, measured using a burn-off technique, was $0.436 \pm 0.004$, where the densities of the fibre and epoxy resin matrix were $676.7 \mathrm{~kg} / \mathrm{m}^{3}$ and 1210 $\mathrm{kg} / \mathrm{m}^{3}$, respectively. The average laminate thickness after fabrication was $1.44 \pm 0.01 \mathrm{~mm}$. With the exception of thickness, the dimensions of the specimens used for the multiple quasi-static indentation tests, and for the single edge notch measurement of the toughness, were the same as for the specimens of PMMA described in Section 2. Additionally, it should be noted that for the tests on the CFRP specimens, the "flaps" formed naturally during the test and there was no need to drill an initial small hole at the centre of the specimen.

A toughness value relevant to quasi-static indentation and penetration of the CFRP panels was measured using the same technique as for the PMMA described in Section 2. For the tests on the composite panels, multiple quasi-static indentation tests were used in which the impactor was driven into a specimen to a certain displacement causing flaps to form, withdrawn and then the impactor was driven to a larger displacement causing the flaps to grow; this was repeated, until complete penetration of the specimen occurred. A digital video camera enabled photographs to be taken of the exit face of the specimen during the test, and flap lengths on both the impact and exit faces of the specimen were recorded for increasing impactor displacements. 
Typical load-displacement curves for loading and unloading at each maximum impactor displacement are shown in Figure 10 (a). It should be noted that, for a given maximum impactor displacement, the unloading and reloading curves do not superimpose which is believed to be due to frictional effects: either indentor/specimen surface interactions or internal friction due to the sliding of internally delaminated interfaces or fractured surfaces. Consequently, the average of the loading and unloading curves has been used in the derivation of the force-displacement response of the specimen flaps, as shown schematically in Figure 10 (b). As an aside, it should be pointed out that the loading-unloading curves of Figure 10(a) can be analysed in terms of the energy balance, as suggested in [16], between the energy absorbed by the specimen $\left(U_{a b s}\right)$ and the work delivered by the impactor $\left(U_{\text {imp }}\right)$, with both terms normalised by the energy required for complete penetration of the specimens $\left(U_{p}\right)$, which for these tests was about $15 \mathrm{~J}$. For all specimens, the relationship between the energies was in reasonable agreement with the suggestion in [16] that $\left(U_{a b s} / U_{p}\right)=\left(U_{\text {imp }} / U_{p}\right)^{n}$, with $n$ in the range 1.5 to 2 .

Figure 11 shows the derived graphs of the load on a single flap, $P^{\prime}$, plotted versus the flap deflection, $\delta_{\text {flap. }}$. The flap load/displacement behaviour is approximately linear, as found for the PMMA specimens. Measurements of the flap lengths, $a$, showed again that the flap lengths on the exit face were longer than those on the impact face, this time by about 2 to $3 \mathrm{~mm}$ for each flap length. The flap compliance for all the specimens tested is shown as a function of average flap length in Figure 12, where the solid line, $C_{\text {flap }}=0.021 a^{2} \mathrm{~m} / \mathrm{N}$, is a reasonable fit to the data. The flexural modulus of the undamaged composite panels was measured in independent four-point bending tests to be $60 \pm 3 \mathrm{GPa}$, so that the empirical correction factor $(\alpha)$ in Equation (2) is $\alpha \approx 0.4$ for this woven fabric CFRP composite.

Table 3 shows the average crack length, $a$ (i.e. the average of the crack lengths measured on the impact and exit faces of the specimen) and the maximum load, $P_{\max }$ for four specimens at increasing flap lengths. As Figure 10 (b) shows, the load to propagate the flaps reduces as the flap length increases. Using Equation (3), the toughness values for these four specimens derived from the quasi-static indentation tests are also shown in Table 3. Figure 13 shows that the toughness increases from about 16 $\mathrm{kJ} / \mathrm{m}^{2}$ at smaller crack lengths to an approximately constant value of about $19 \mathrm{~kJ} / \mathrm{m}^{2}$ for the longer crack lengths (9mm to $13 \mathrm{~mm}$ ); the average toughness is $18.7 \pm 1.6 \mathrm{~kJ} / \mathrm{m}^{2}$ for all crack lengths, where the 
uncertainty is the standard deviation. The average toughness of the same composite panels found using single edge notch experiments was $16.1 \pm 2.4 \mathrm{~kJ} / \mathrm{m}^{2}$ (this can be compared with a value of about $18 \mathrm{~kJ} / \mathrm{m}^{2}$ found for an eight-layer plain weave quasi-isotropic CFRP laminate [17] having approximately the same fibre volume fraction, tested using the SEN method). Consequently, as for the PMMA specimens, the mode I toughness of the CFRP specimens measured using the quasi-static indentation tests is higher than the value obtained using the SEN tests, this time by about $16 \%$. Again, a mode II toughness contribution is indicated, although there does not appear to be any independent data against which this can be substantiated.

Microscopy of the cross-sections of impacted CFRP specimens was used to investigate the extent to which delaminations and other damage developed within the flaps of these woven fabric reinforced CFRP specimens. Figure 14 (a) shows the exit face of a composite specimen which had been subjected to a displacement of $8 \mathrm{~mm}$ (producing average flap lengths of about $7 \mathrm{~mm}$ and $5 \mathrm{~mm}$ on the exit and impact faces, respectively). The specimen was sectioned in order to observe the damage in a cross-section located at a distance of about $2 \mathrm{~mm}$ from the centre of the indentation (as indicated in Figure 14 (a)). This cross-section, shown in Figure 14 (b), includes two of the flap fracture faces; the fracture path between the impact and exit faces can be seen to include tow fractures, delaminations and matrix cracking; extensive delaminations can also be seen away from the main fracture path. The results in Figure 12 suggest that this additional damage increases the compliance of the flaps by about $15-20 \%$, especially for the longer flap lengths. It is possible to estimate the contribution of delamination and matrix cracking to the absorbed energy, assuming that there is saturation matrix cracking throughout the volume enclosed within the lines of the tow fractures and that every interface between plies is delaminated (a very large overestimate). For the longest flap lengths investigated $(12 \mathrm{~mm})$, taking the mode I fracture energy for matrix cracking to be $130 \mathrm{~J} / \mathrm{m}^{2}$ [18] and mode II fracture energy for delamination to be $155 \mathrm{~J} / \mathrm{m}^{2}$ [19], the energy absorbed is approximately $0.5 \mathrm{~J}$. This can be compared with the experimentally measured absorbed energy for complete penetration of about $15 \mathrm{~J}$, suggesting that delamination and matrix cracking contribute less than $5 \%$ of the energy absorbed. 


\section{Concluding remarks}

This paper has reported results of experiments using quasi-static indentation experiments at very low impactor velocities. In common with the results of low-velocity and ballistic velocity tests, the results show that triangular "flaps" can form as a consequence of through-thickness penetration (i.e. perforation) of thin woven CFRP panels laid-up in a 0/90 configuration. The compliance of these flaps is predicted to vary with the square of the flap (i.e crack.) length and this has been found to be in reasonable agreement for experiments on PMMA and on thin woven fabric reinforced CFRP panels. In order to account for the lack of rigidity at the base of the flaps, an empirical flap-length correction factor has been introduced. Combining the compliance/flap length measurements with the load required to grow the flaps, a toughness value can be obtained for the growth of the flaps during quasi-static indentation tests. Experimental observations of the crack profile on the impact and exit faces, together with comparisons of the toughness values obtained from the indentation tests with the values found using SEN experiments, suggests that the toughness value derived in the indentation tests is not a pure Mode I value.

The technique developed here for determining a toughness relevant to a quasi-static indentation may be useful in subsequent work on improving the penetration resistance of a woven fabric CFRP laminate through additions to the matrix (e.g. using carbon nanotubes). The approach outlined here has been developed using quasi-static indentation tests but is likely to be relevant to low-velocity impact events as well; although similar flaps have also been observed for high-velocity impact, the analysis does not currently incorporate the additional complications of ballistic impacts.

\section{Acknowledgements}

The authors would like to thank the Royal Thai Government for the provision of a studentship for J. Sirichantra, and to thank our colleague, Mr Peter Haynes, for invaluable technical assistance.

\section{References}

1. Goldsmith W, Dharan CK and Chang H. Quasi-static and ballistic performance of carbon fibre laminates. International Journal of Solids and Structures 1995; 32: 89-103. 
2. Iannucci L, Willows ML. An energy based damage mechanics approach to modelling impact onto woven composite materials: Part II Experimental and numerical results. Composites Part A 2007; 38: 540-554.

3. Lopez-Puente J, Zaera R, Navarro C. Experimental and numerical analysis of normal and oblique ballistic impacts on thin carbon/epoxy woven laminates. Composites Part A 2008; 39A: 374-387.

4. Evans AG and Charles. Fracture toughness determinations by indentation. Journal of the American Ceramics Society 1976; 59: 371-372.

5. Anstis GR, Chantikul P, Lawn BR, Marshall DB. A critical evaluation of indentation techniques for measuring fracture toughness: I direct crack measurements. Journal of the American Ceramics Society 1981; 64: 533-538.

6. Richardson MOW, Wisheart MJ. Review of low-velocity impact properties of composite materials. Composites Part A 1996; 27A:1123-1131.

7. Hull D, Shi YB. Damage mechanism characterization in composite damage tolerance investigations. Composite Structures 1993; 23: 99-120.

8. Davies GAO, Hitchings D, Zhou G. Impact damage and residual strengths of woven fabric glass/polyester laminates. Composites Part A 1996; 27A: 1147-1156.

9. Gere JM and Timoshenko SP. Mechanics of Materials. PWS-Kent Publishing Company, 1990

10. CRAG test 403: Method of test for residual compression strength after impact of multi-directional fibre reinforced plastics. In: PT Curtis, CRAG Test Methods for the Measurement of the Engineering Properties of Fibre Reinforced Plastics. Royal Aerospace Establishment Technical Report, 1988. RAETR-88-012.

11. Sofocleous K, Ogin SL, Tsakiropoulos P, Crocombe AD, Le-Page BH. Controlled impact testing of shape memory alloy composites. In: Proceedings of ECCM-12 Conference. Biarritz, France, 2006. Vol 1. paper 426.

12. Kai-Tak W, Shu G, David AD. A theoretical and numerical study of a thin clamped circular film under an external load in the presence of a tensile residual stress. Thin Solid Films 2003; 425: 150-162. 13. Caprino G, Langella A, Lopresto V. Elastic behaviour of circular composite plates transversely loaded at the centre. Composites Part A 2002; 33: 1191-1197.

14. Archer JS, Lesser AJ. Shear band formation and mode II fracture of polymeric glasses. Polymer Science Part B: Polymer Physics 2010; 49: 103-114.

15. Belmonte HMS, Manger CIC, Ogin SL, Smith PA, Lewin R. Characterisation and modeling of the notched tensile fracture of woven quasi-isotropic GFRP laminates. Comp Sci Tech 2001; 61: 585-597. 16. Martello L, Mian S, Quaresimin M, Ricotta M. Energy absorption during low velocity impact of composite laminates. In: Proceedings of ECCM-12 Conference. Biarritz, France, 2006. Vol 1. paper 513. 17. Belmonte HMS, Ogin SL, Smith PA, Lewin R. A physically-based model for the notched strength of woven quasi-isotropic CFRP laminates. Composites: Part A 2004; 35; 763-778.

18. Le Page BH, Guild FJ, Ogin SL, Smith PA. Finite element simulation of woven fabric composites. Composites: Part A 2004; 35; 861-872.

19. Nikbakht M, Choupani N. Experimental investigation of mixed-mode fracture behaviour of woven laminated composite. Materials Science 2009; 44: 3428-3437. 


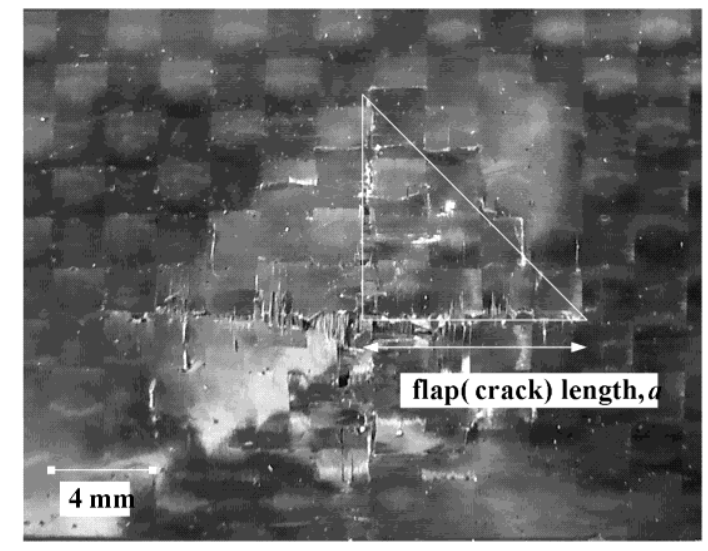

(a)

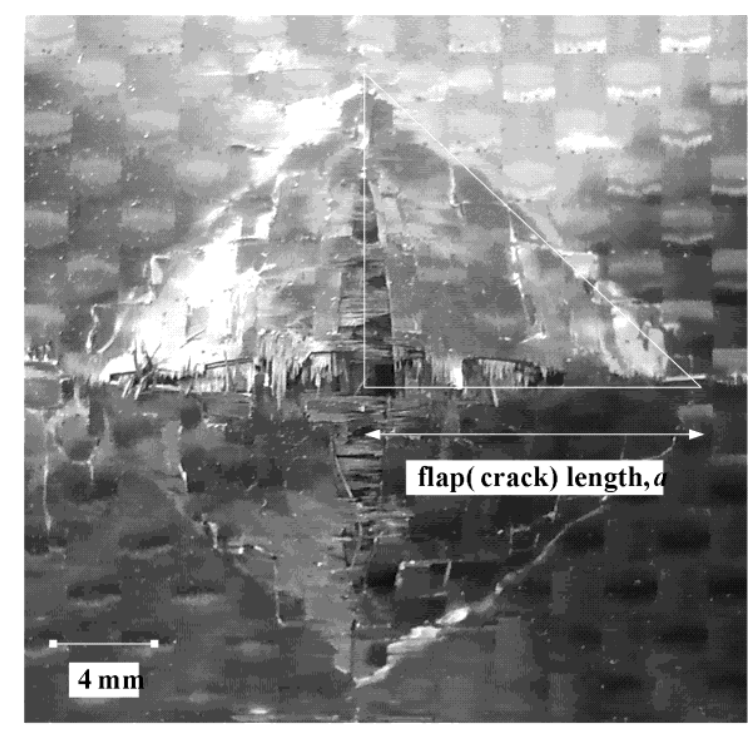

(b)

Figure 1

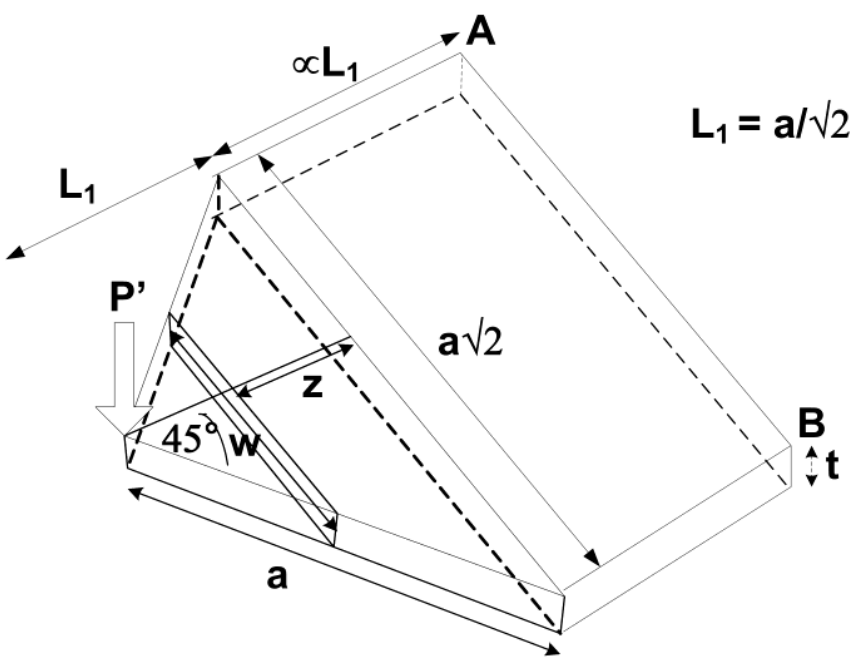

Figure 2 


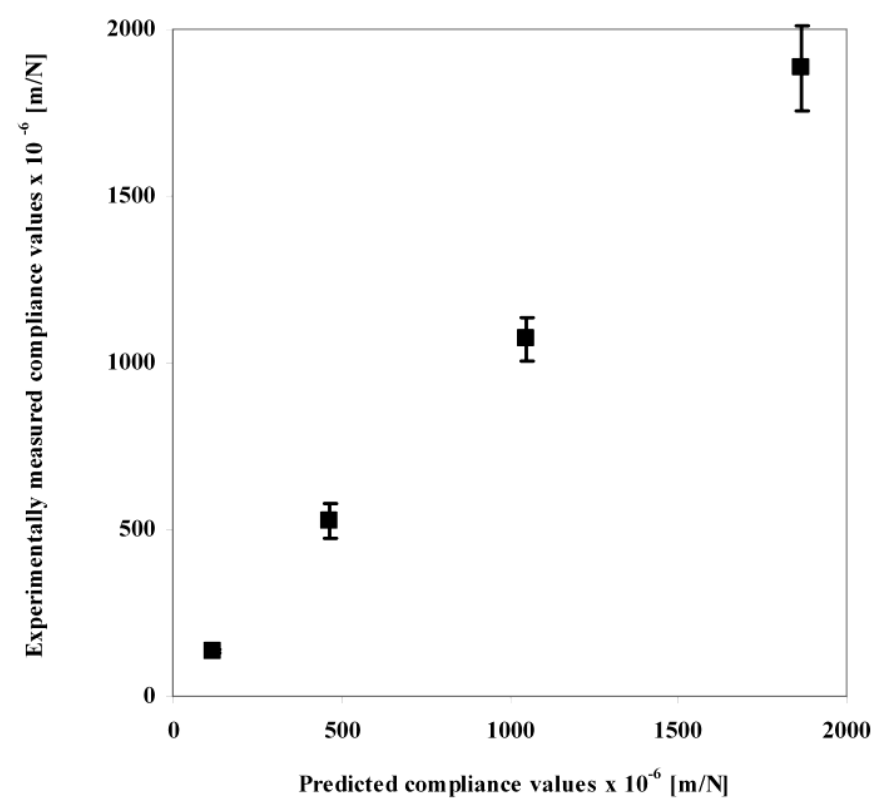

Figure 3

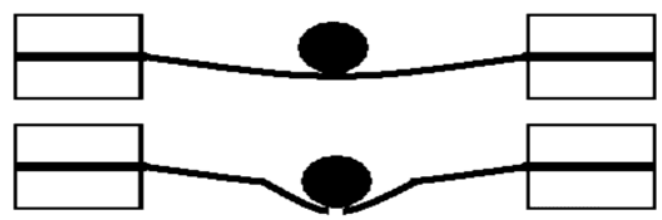

(a)

(b)

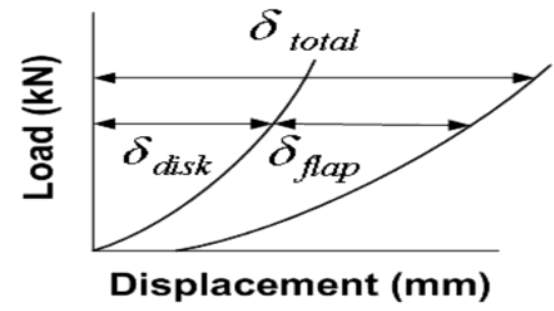

Figure 4

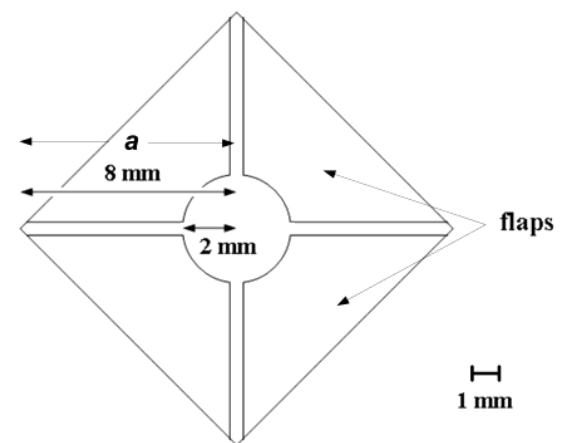

Figure 5 


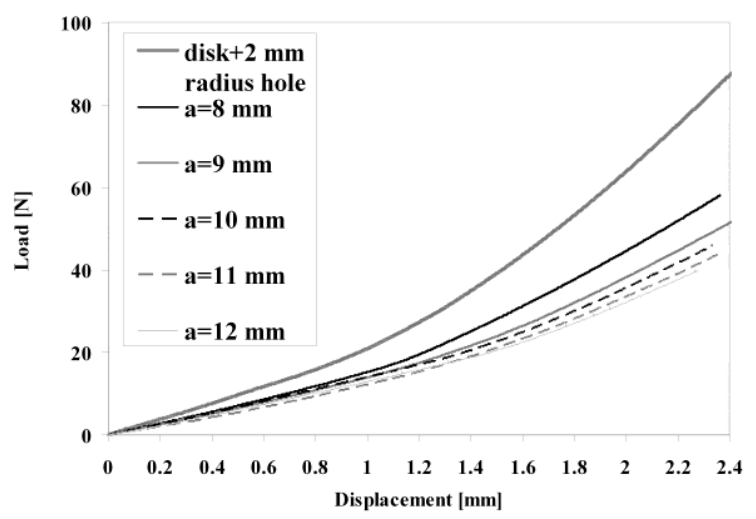

(a)

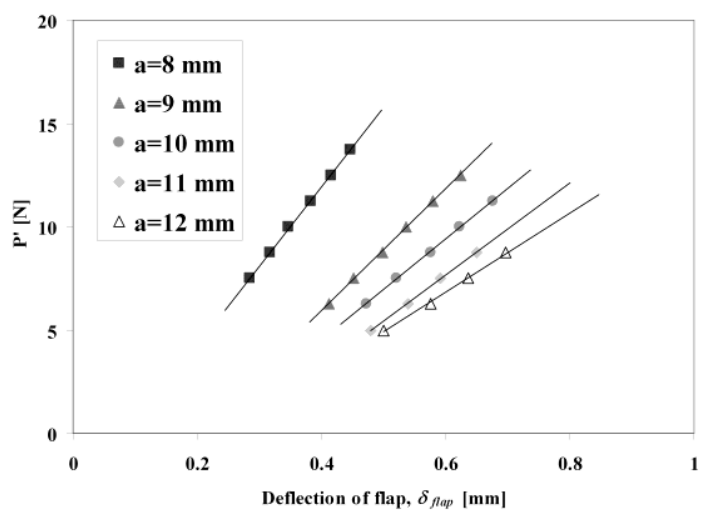

(b)

Figure 6

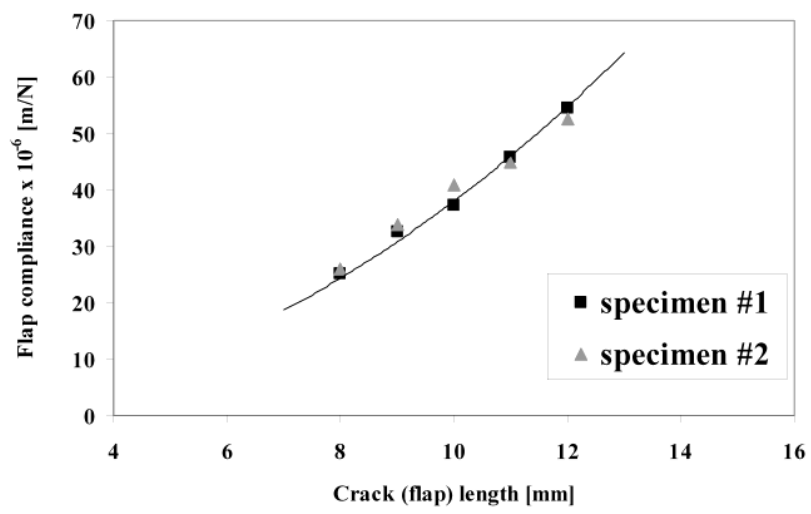

Figure 7 


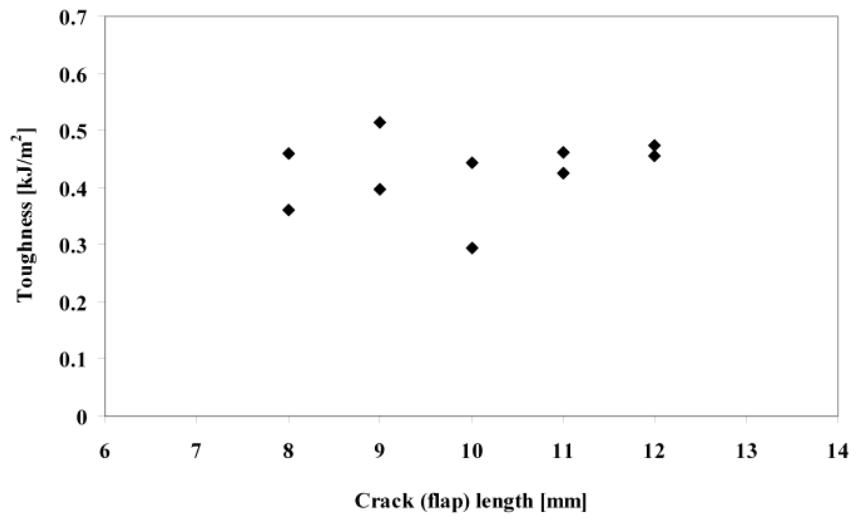

Figure 8

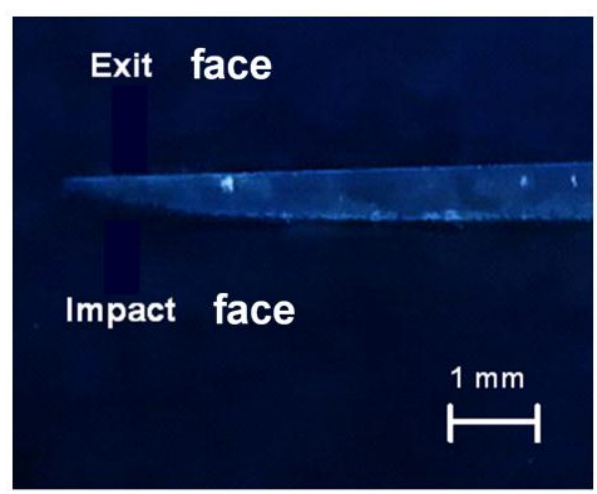

Figure 9 

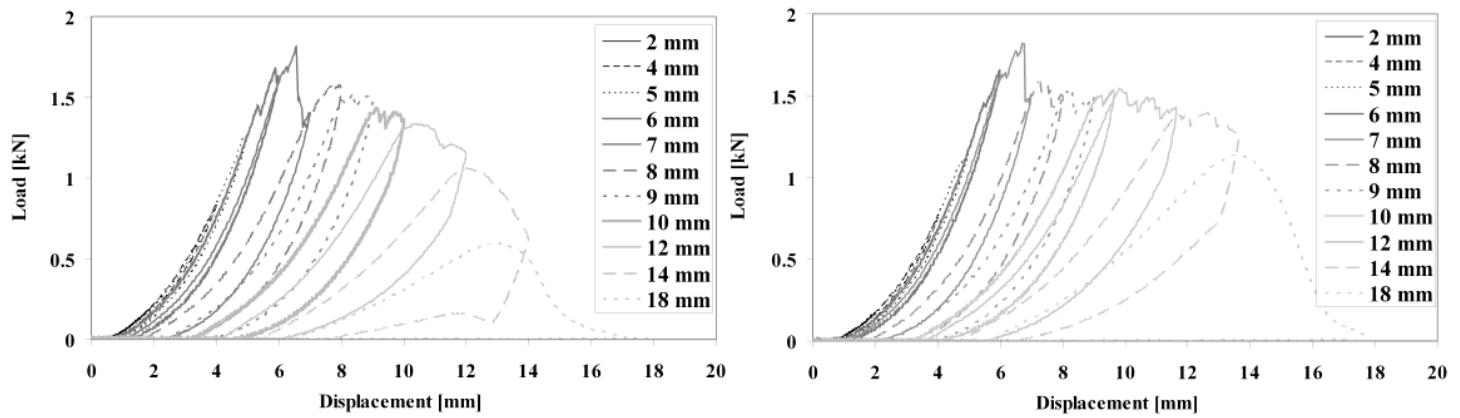

Specimen \#1
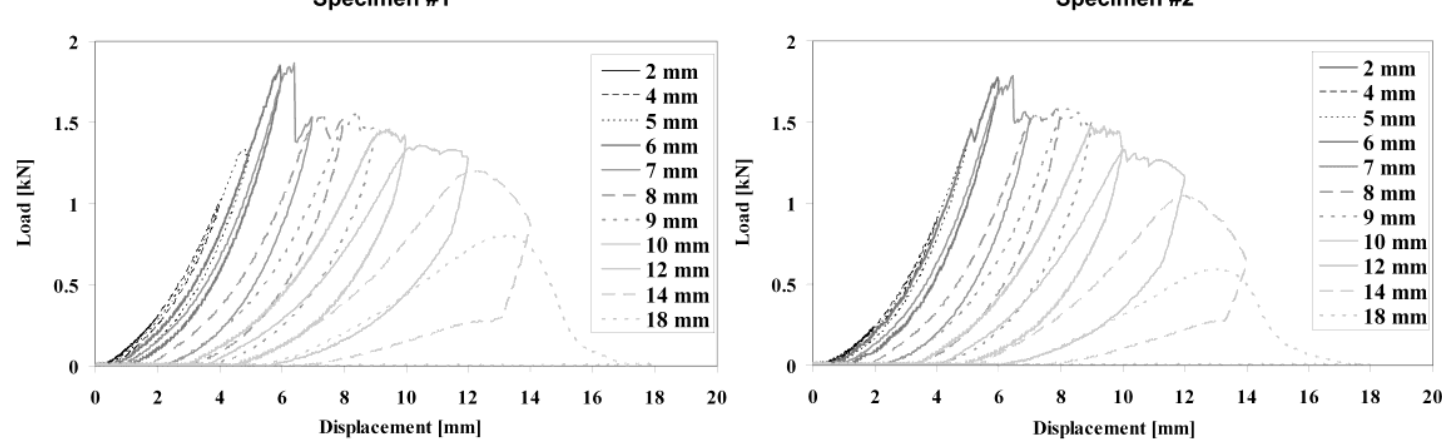

Figure 10 (a)

Specimen \#3

Specimen \#4
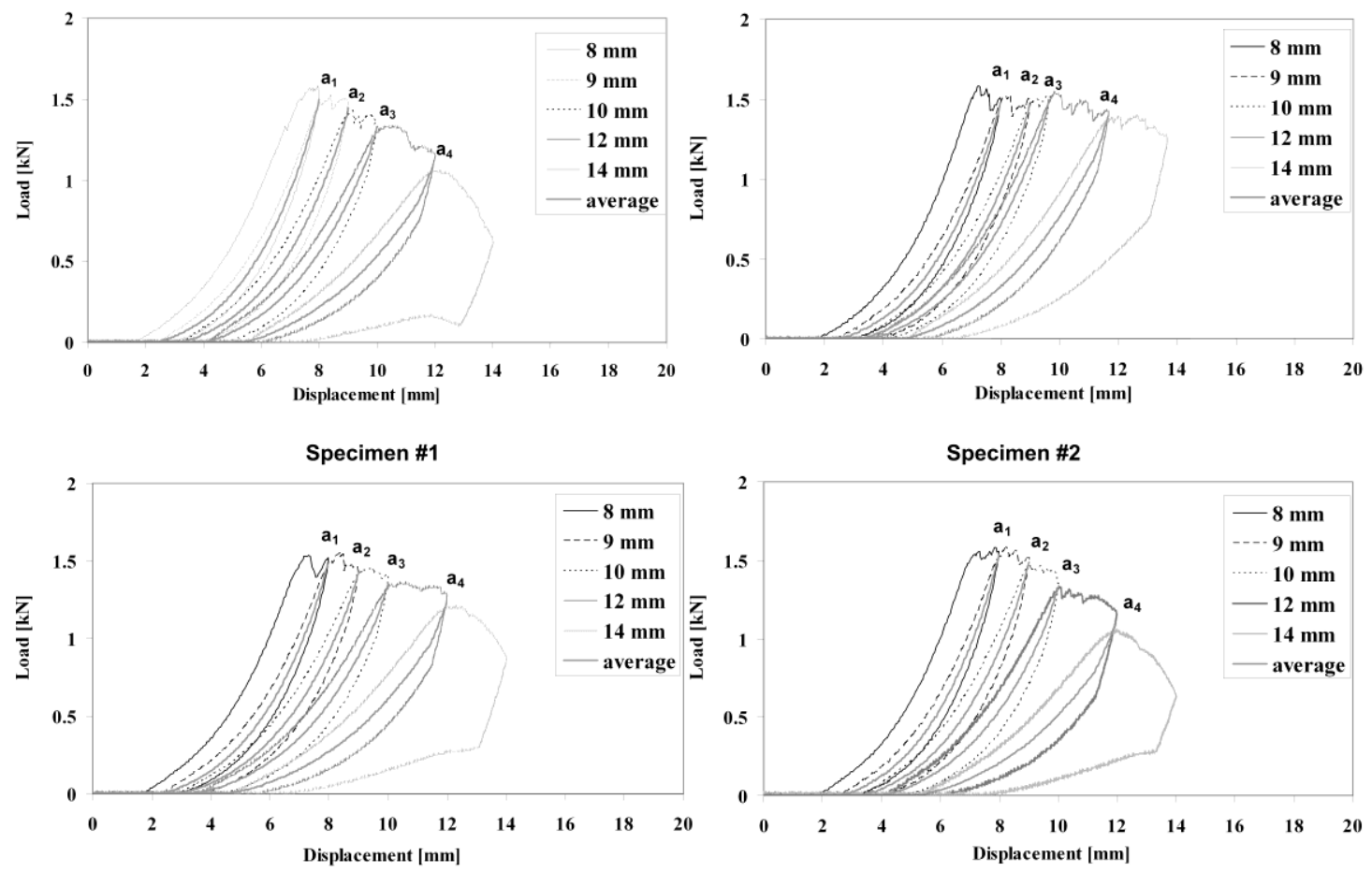

Figure 10 (b)

Specimen \#3

Specimen \#4 

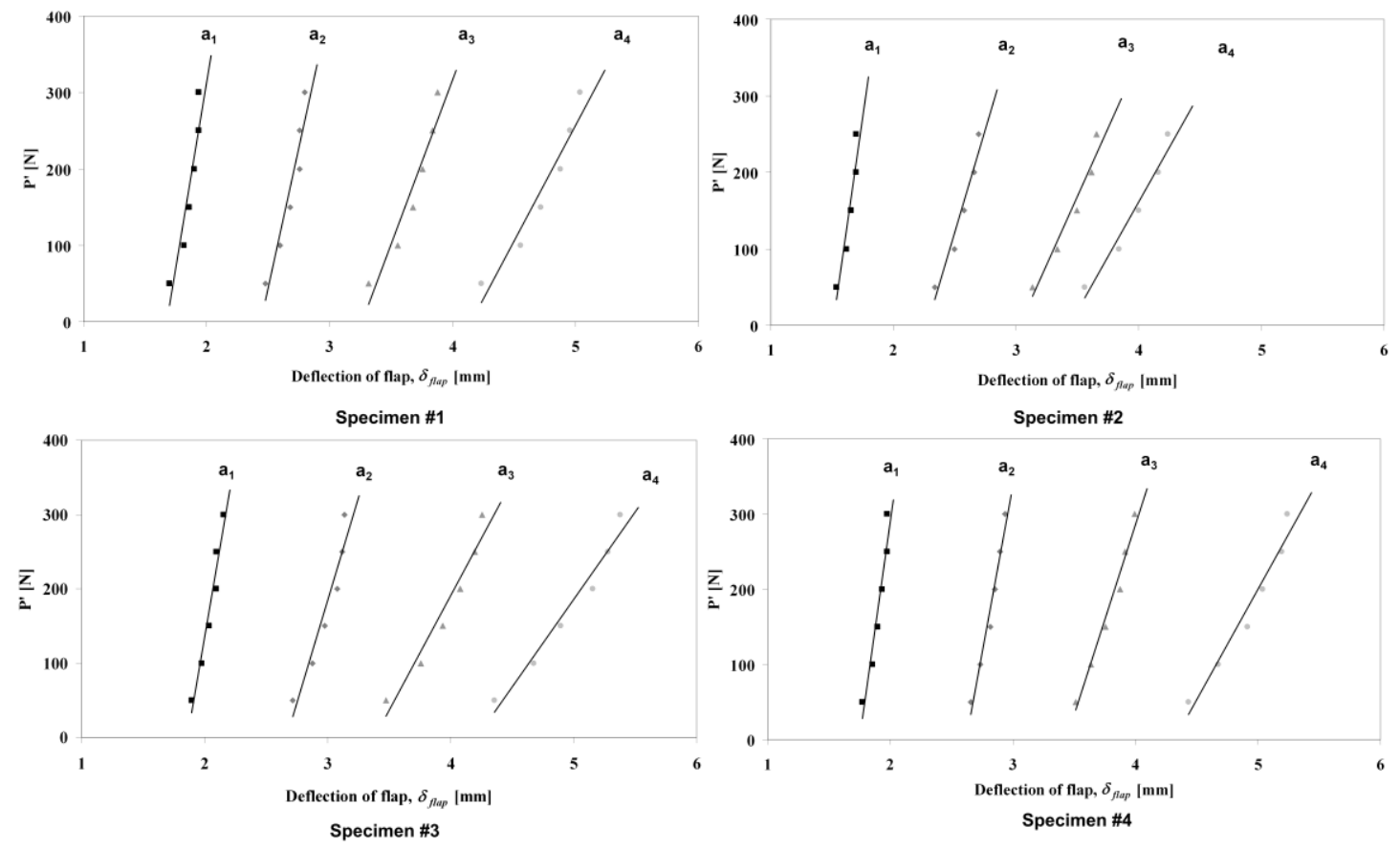

Figure 11

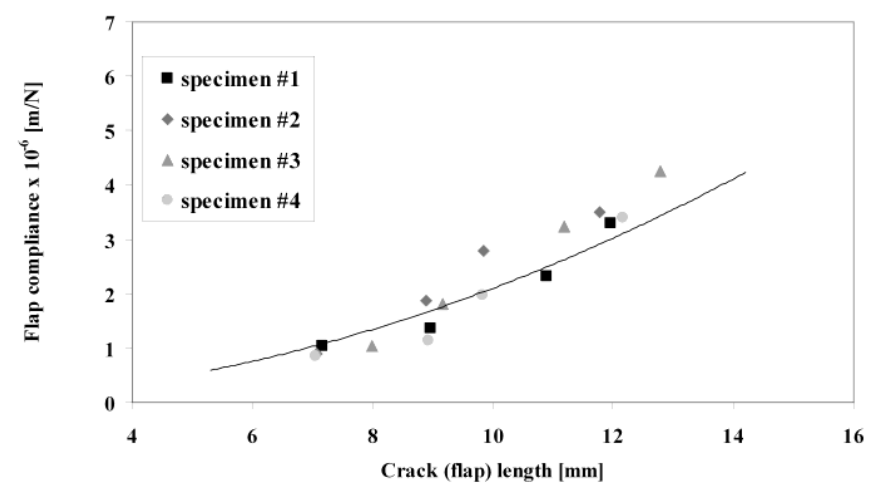

Figure 12 


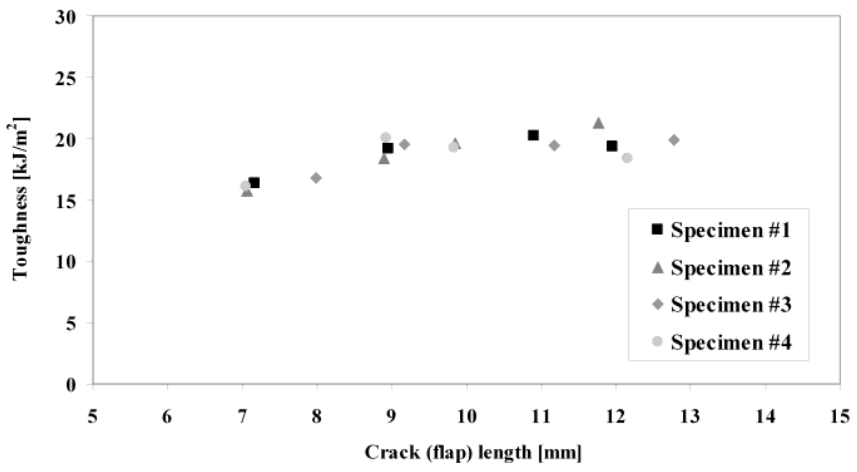

Figure 13

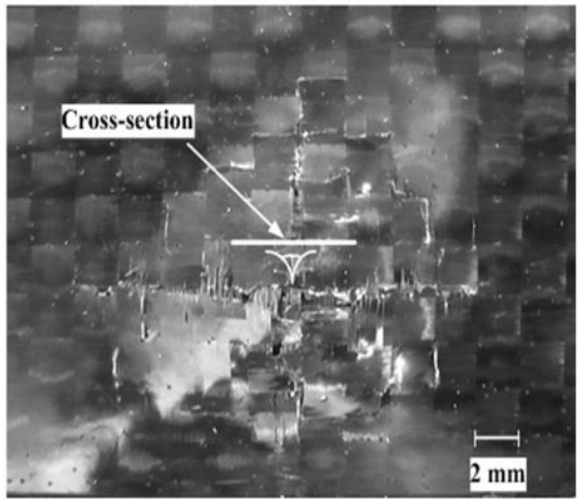

(a)

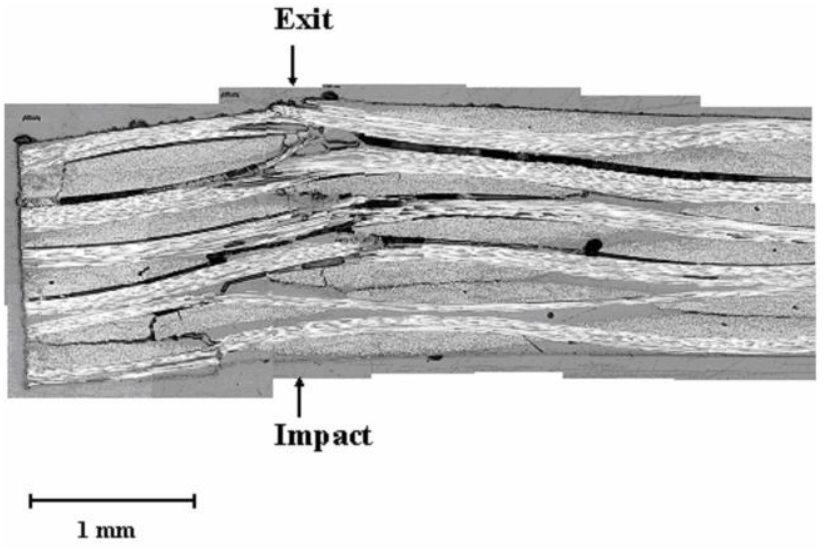

(b)

Figure 14 


\section{Figure caption}

Figure 1. View of exit face of a specimen for which the flap (crack) length has increased from (a) $8 \mathrm{~mm}$ to (b) $10 \mathrm{~mm}$. In each case, one of the four flaps is delineated.

Figure 2. Sketch of a triangular flap with a rectangular extension.

Figure 3. Experimentally measured compliance values compared to predicted compliance values.

Figure 4. Schematic of a cross-section through the centre of a disk subjected to the same impact force (a) before flaps develop, and (b) after flaps develop; (c) load-displacement response of a disk without flaps $\left(\delta_{\text {disk }}\right)$ and with flaps $\left(\delta_{\text {total }}\right)$.

Figure 5. A sketch of the flaps formed from 4 notches, each $8 \mathrm{~mm}$ long; the specimen has a $4 \mathrm{~mm}$ diameter hole at the centre of the disk.

Figure 6. (a) Typical load-displacement curves for a range of flap lengths; (b) the load on one flap, $P$, plotted against flap deflection for increasing crack lengths.

Figure 7. Graph of flap compliance against crack (flap) length; the solid line shows an expression of the form $C \propto a^{2}$.

Figure 8. Toughness values of PMMA as a function of crack (flap) length.

Figure 9. Image of an illuminated crack developed during the quasi-static indentation tests on PMMA; the tapered profile of the crack front shows that the crack is longer on the exit face than on the impact face.

Figure 10. (a) Load-displacement curves for increasing impactor displacements for four specimens; (b) the same showing the average (solid lines) of the unloading-loading parts of the curve.

Figure 11. Load on one flap, $P^{\prime}$, plotted against the flap deflection for the four specimens of Figure 10.

Figure 12. Graph of flap compliance against crack (i.e. flap) length; the solid line shows an expression of the form $C \propto a^{2}$.

Figure 13. Toughness values measured using the quasi-static indentation tests for the CFRP specimens for different crack (flap) lengths.

Figure 14. (a) Exit face view of a specimen which was tested to a displacement of $8 \mathrm{~mm}$ producing flaps with a length, $a$, of about $7 \mathrm{~mm}$; (b) a cross-section of the same specimen located about $2 \mathrm{~mm}$ from the centre of impact, with the impact and exit faces of the specimen indicated.

\section{Table captions}

Table 1. Flap lengths and extension lengths for compliance measurements on PMMA flaps.

Table 2. Toughness measurements of PMMA derived from the quasi-static indentation tests, showing the results for two specimens for each crack length.

Table 3. Toughness measurements for the thin woven fabric CFRP panels for four specimens derived from the multiple quasi-static indentation tests; for each specimen, the toughness measured at four (increasing) crack lengths is shown. 
Table 1

\begin{tabular}{ll}
\hline $\begin{array}{l}\text { Crack (flap) } \\
\text { length } \\
a[\mathrm{~mm}]\end{array}$ & $\begin{array}{l}\text { Extension length } \\
\boldsymbol{\alpha} \boldsymbol{L}_{\boldsymbol{I}}[\mathbf{m m}]\end{array}$ \\
\hline 25 & 17.7 \\
50 & 35.4 \\
75 & 53.0 \\
100 & 70.7 \\
\hline
\end{tabular}

Table 2

\begin{tabular}{lll}
\hline Crack length & Load & Toughness \\
$a[\mathrm{~mm}]$ & $P_{\max }[\mathrm{N}]$ & $G_{c}\left[\mathrm{~kJ} / \mathrm{m}^{2}\right]$ \\
\hline 8 & & \\
\hline \multirow{3}{*}{9} & 71.71 & 0.46 \\
& 66.03 & 0.36 \\
10 & 68.73 & 0.51 \\
& 68.43 & 0.40 \\
11 & 58.94 & 0.44 \\
& 62.24 & 0.29 \\
12 & 68.95 & 0.46 \\
& 63.39 & 0.43 \\
& 60.00 & 0.46 \\
\hline
\end{tabular}

Table 3

\begin{tabular}{llll}
\hline Specimen & $\begin{array}{l}\text { Average } \\
\text { crack length } \\
\text { a [mm] }\end{array}$ & $\begin{array}{l}\text { Load } \\
P_{\text {max }}[N]\end{array}$ & $\begin{array}{l}\text { Toughness } \\
G_{c}\left[\mathrm{~kJ} / \mathrm{m}^{2}\right]\end{array}$ \\
\hline$\# 1$ & 7.2 & 1.58 & \\
& 9.0 & 1.52 & 16.4 \\
& 10.9 & 1.42 & 20.3 \\
$\# 2$ & 12.0 & 1.33 & 19.3 \\
& 7.1 & 1.56 & 15.7 \\
& 8.9 & 1.52 & 18.4 \\
& 9.9 & 1.49 & 19.6 \\
& 11.8 & 1.42 & 21.3 \\
& 8.0 & 1.53 & 16.8 \\
& 9.2 & 1.54 & 19.5 \\
& 11.2 & 1.40 & 19.5 \\
& 12.8 & 1.32 & 19.9 \\
& 7.1 & 1.55 & 16.1 \\
& 8.9 & 1.56 & 20.1 \\
& 9.8 & 1.45 & 19.2 \\
& 12.2 & 1.27 & 18.4 \\
\hline \multirow{4}{*}{ \#4 } & & &
\end{tabular}

